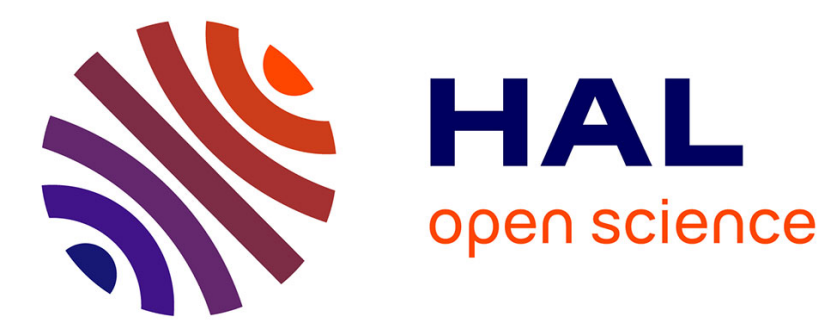

\title{
Desktop cutting of paper using a single emitter laser diode and inkjet printing
}

Olivier Acher, Hubert Pagès, Franck Enguehard, Hervé Piombini

\section{To cite this version:}

Olivier Acher, Hubert Pagès, Franck Enguehard, Hervé Piombini. Desktop cutting of paper using a single emitter laser diode and inkjet printing. Proceedings of SPIE, the International Society for Optical Engineering, 2005, High-Power Diode Laser Technology and Applications III, 109, 10.1117/12.588490 . hal-01251578

\section{HAL Id: hal-01251578 https://hal.science/hal-01251578}

Submitted on 7 Jan 2016

HAL is a multi-disciplinary open access archive for the deposit and dissemination of scientific research documents, whether they are published or not. The documents may come from teaching and research institutions in France or abroad, or from public or private research centers.
L'archive ouverte pluridisciplinaire HAL, est destinée au dépôt et à la diffusion de documents scientifiques de niveau recherche, publiés ou non, émanant des établissements d'enseignement et de recherche français ou étrangers, des laboratoires publics ou privés. 


\title{
Desktop cutting of paper using a single emitter laser diode and inkjet printing
}

\author{
O. Acher ${ }^{*}$, H. Pages, F. Enguehard and H. Piombini \\ CEA Le Ripault, BP 16 \\ F-37260 Monts France
}

\begin{abstract}
Laser cutting of paper is widely used in the paper conversion industry. $\mathrm{CO}_{2}$ lasers are well suited for this type of applications. Desktop printing is a large market both for digital photography, document management and graphics applications, but it still lacks advanced cutting and scoring ability, and $\mathrm{CO}_{2}$ lasers seem costly to be integrated in massmarket printers.

For that reason, mass-scalable and low-cost semiconductor laser diodes would be very advantageous to add paper cutting and scoring features in desktop printers. However, common paper can not be cut properly using visible or Near Infrared (NIR) laser diode since it has a very poor absorption at these wavelengths.

We report here an innovative solution to achieve paper cutting or scoring using a $1 \mathrm{~W}$ single emitter NIR laser diode, within an inkjet printer. A special ink that absorbs the NIR light, and that penetrates all through the paper, is first disposed on the lines to be cut. Then, the laser diode goes along the lines to be cut. We show that a cutting speed of $2 \mathrm{~m} / \mathrm{min}$ can be achieved on $80 \mathrm{~g} / \mathrm{m}^{2}$ conventional paper. The influence of the optical properties of the ink on the cutting speed are discussed, as well as focussing issues. In particular, we show that invisible inks are suitable, and very clear-cut edges can be obtained. The perspective of this technique are discussed.
\end{abstract}

Keywords: Laser diode, paper, cutting

\section{INTRODUCTION}

\subsection{An attractive opportunity in laser processing of materials : desktop cutting of paper using a diode laser}

Laser processing of materials has been recognized as a powerful technique in the industry for years ${ }^{1}$, and this technique is fast expanding. High Power Diode Lasers have attracted considerable interest in the field of material processing, they are very attractive in term of small size, reliability, and cost. However, it has been stated that the market of High power Laser diodes is a very small share of the overall laser diode market, and that the part of this market associated to material processing of material is also very small ${ }^{2}$. This is mainly because beam quality is still an issue with diode lasers when a large number of emitters are combined. In contrast, single emitter lasers are not affected by this limitation. Single emitter diodes with powers up to $10 \mathrm{~W}$ have been reported ${ }^{3}$, and are commercially available up to $5 \mathrm{~W}$. It is clear that a material processing applications that would be satisfied using a single emitter laser diode, and that would be driven by a mass market, would benefit from the tremendous downscaling of the costs that are observed for all integrated semiconductor components.

In this paper, we show that such a material processing application exists : the material is paper, and the process is cutting or scoring the paper to the desired format and shape

Though paper is a very old and common material, it is also a modern media with strong connections with digital applications ${ }^{4}$. This fact is supported by figure 1 , that gives some key figures on the paper consumption in different countries. It should be noted that 30 to $40 \%$ of this consumption in the US and in Europe are dedicated to graphics uses. For the US only, the value of cut sheet paper is 10,8 billion dollars in 2002, and should grow to 12.2 billion dollars by $2006^{5}$. Digital printing can also be viewed as a form of material processing. Key revenue figures related to worldwide home and office inkjet printing market are given on Fig. 2. The 32.2 billion dollar revenue of 2003 is expected to increase steadily in the next years, with an anticipated revenue of 46.6 billion dollars in 2008. Special media, including photo paper, greeting card-boards, labels of all kinds, pre-cut paper with a variety of formats for applications ranging

*livier.acher@cea.fr; phone + 332473448 30; fax + 33247345156 
from name badges to CD-Rom jackets, represent more than $10 \%$ of this value. This illustrates the need for special format printer output, which is presently addressed by proposing a large variety of media consisting of pre-cut paper.

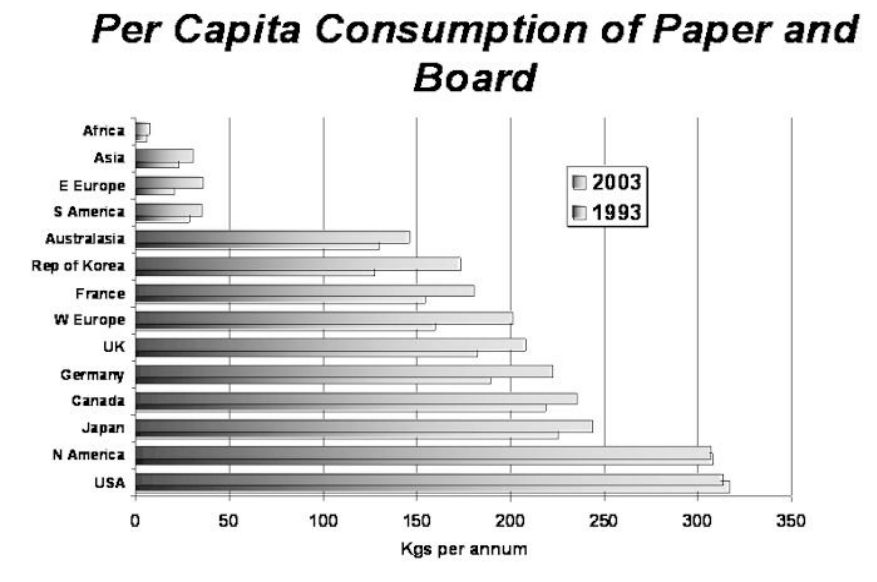

Source: National Associations, FAO ( 2003 Continental data estimated based on 2002)

Figure 1: Key figures of the overall paper consumption in different countries.

Worldwide Narrow Format Ink Jet Revenues Hardware, Media \& Ink (\$)

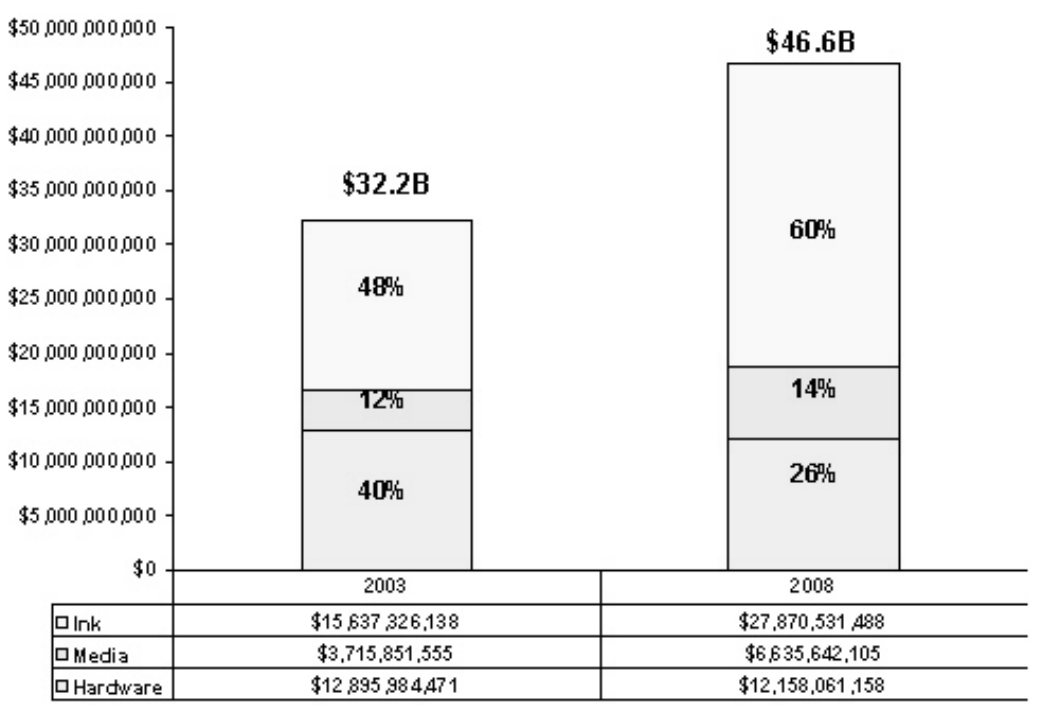

Figure 2: Key figures of inkjet digital printing.

This figures show that paper cutting using a laser diode may be the first mass-market desktop application of laser processing of materials. Of course semiconductor lasers are already widely used for desktop printing in laser printer, but in that case the laser is used to write on the photosensitive material, and it is not used in direct interaction with the paper. Though it may sound less fanciful than laser cutting and joining of high-tech aerospace alloys, or micro-machining electronic devices, it is clearly a desirable feature in our "Digital Era" that future printers shall be able to cut paper to any desired format, and expand creation possibilities concerning paper shape just like it did concerning the variety and quality of images it can create on paper. 


\subsection{Turning cost constrains into innovation opportunities}

$\mathrm{CO}_{2}$ lasers are widely used in the paper conversion industry, for paper cutting and scoring ${ }^{1}$. They are well suited for this application, since paper is absorbing at $10.6 \mu \mathrm{m}$ wavelength. Besides, they exhibit high powers, good beam quality, satisfactory price/power ratio, and they allow cutting speeds of several hundred meters per minutes or more that are well suited to industry. The requirements for high power voltage, thermal management, and maintenance, are easily dealt with in industrial environments. Recently, desktop "plug and play" laser cutting apparatus have been marketed ${ }^{6}$. These systems can cut light wood, plastics, cardboard and paper. However, their costs are still two orders of magnitudes higher than a digital inkjet printer. The requirement for a high voltage supply, the need for precision mechanical mounting of laser mirrors, the low wallplug efficiency of the laser and the subsequent requirements on thermal management, are strong barriers for cost reduction.

In contrast, mass produced single emitter laser diodes with a few Watts of optical power have a very limited cost, and support very few mounting, power supply, and thermal management costs. As a consequence, they would be very attractive as sources for paper cutting. However, the problem is that conventional paper is white not only in the visible range, but also in the near infrared. As a consequence, conventional NIR emitting diodes do not interact with the paper and cannot cut it.

We brought an innovative solution to this problem by using a proper ink that absorbs the radiation of the laser. The cutting of the paper is performed by first tracing the line to be cut on the paper with the absorbing ink, and then the ray of the NIR laser is used to cut the paper. We named it technology Trace and Ray Cut Technology, or TRACTechnology ${ }^{7}$. The inking operation with the absorbing ink can be done by inkjet printing. So if you start from a conventional printer as a basis for conception of a Print and Cut system, the integration of an additional printhead is not expensive, and all the displacement of the laser relatively to the paper can be handled with the paper management and tray management of the printer. As a consequence, extra costs of the Cut function are related to the Laser diode, which makes this system very affordable. This invention is described in more detail elsewhere ${ }^{8}$.

The aim of this paper is to give experimental evidences of the feasibility of paper cutting using a single emitter diode laser, and a proper ink. The integration of all these functions into an inkjet printer are an industrial issue that is not further discussed.

\section{EXPERIMENTAL DETAIL}

Our laser cutting demonstration system is based on a $1 \mathrm{~W}$ single emitter diode at $810 \mathrm{~nm}$. The emitter width is $100 \mu \mathrm{m}$, and the focusing optics consists in two aspherical condensers $\left(\mathrm{L}_{1}: \mathrm{F} 23\right.$ and $\left.\mathrm{L}_{2}: \mathrm{F} 8\right)$. The power available on the paper is determined using a bolometer. The maximum power available is $0.8 \mathrm{~W}$, as no special care was taken to minimize parasitic reflections on the lenses. A beam splitter and a camera can also be used to visualize the focused beam on the paper. The paper is put on an Aluminium drum with black coating. A "low thermal conductivity drum" consisting of a mat of glass fiber was also used. Conventional Microncontrôle mounts have been used to provide easy adjustment possibilities of the focusing and control of the drum speed, and no attempt has been made to achieve compactness in this laboratory apparatus. A sketch and a view of the optical bench are given on Figure 3.

Our experiments have been performed on plain white office paper, $80 \mathrm{~g} / \mathrm{m}^{2}$ grade. Several types of inks have been used to investigate the laser cutting. Black and green office marker have been used. The marking process was slow enough, so that the ink penetrated in the paper and the color began to appear at the back of the paper. We formulated an "invisible ink" using a commercially available pigment from Aldrich, denominated IR820, that absorbs in the NIR and is nearly transparent in the visible range. The dye was dissolved in a mixture of water and propan-1-ol (20\%). This solvent was chosen because it allowed a better penetration of the ink within the paper, due to a lower surface tension. Lines to be cut were drawn on the paper using a thin brush or a fountain pain. Care was taken that the ink penetrates deep enough in the paper. 


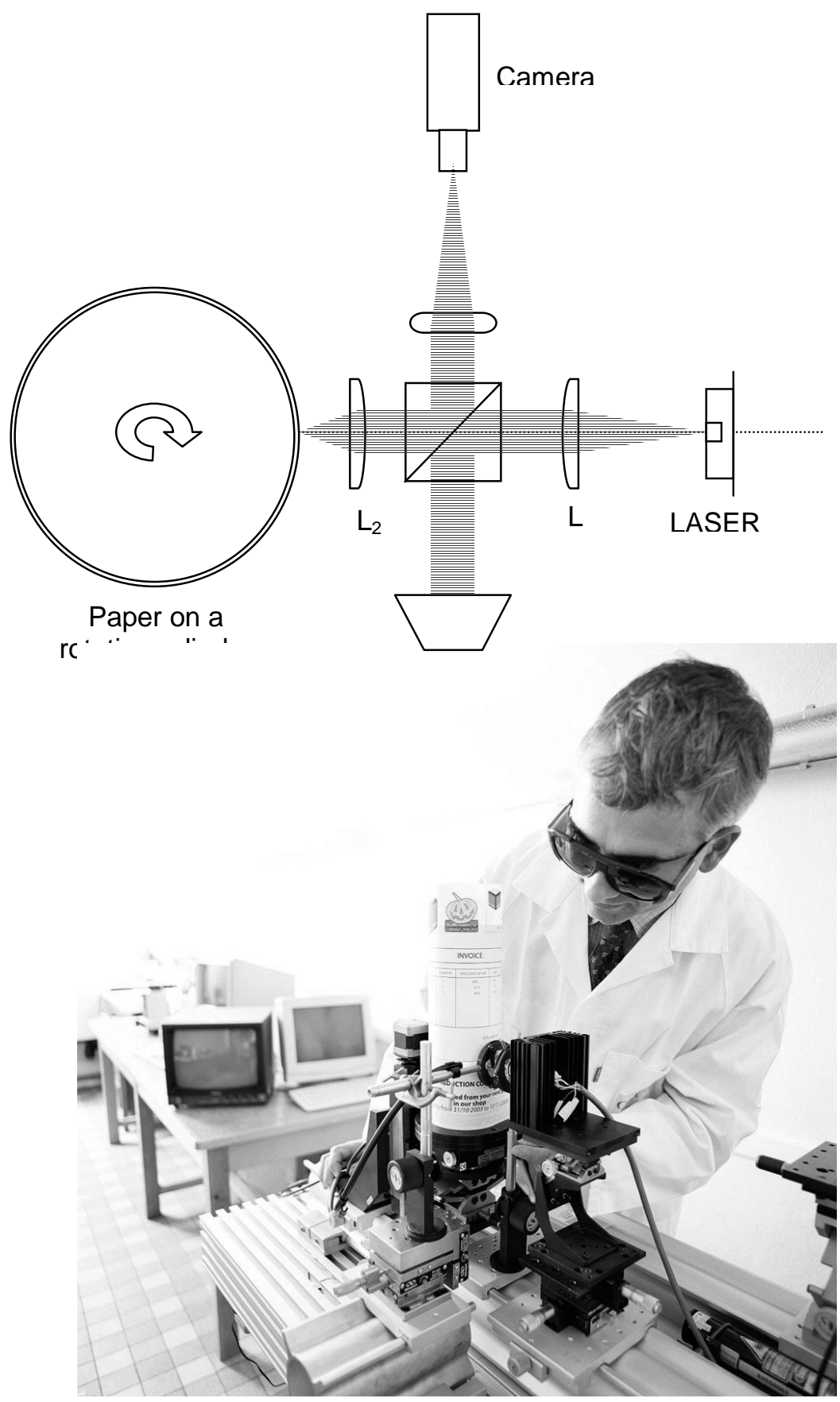

Figure 3: top: sketch of the experimental setup; bottom view of the experimental system (without the beam splitter, camera and bolometer).

Optical properties of white paper inked with different dyes have been measured with a VARIAN spectrophotometer in the 300 to $1500 \mathrm{~nm}$ range. An integration sphere has been used to collect both specular rays and diffusion, to determine the total transmittance $\mathrm{T}$ and total reflectance $\mathrm{R}$. The absorbency (A) is deduced from A=1-T-R. Results are presented on figure 4 . It can be observed that the white paper absorbs less than $5 \%$ of the visible and NIR light. About $80 \%$ of the 
light is reflected and $20 \%$ is transmitted. The black marker ink allows $90 \%$ or more absorption. The invisible IR ink allows about $80 \%$ absorption at the wavelength of the laser, and leaves only a very light pale green appearance.

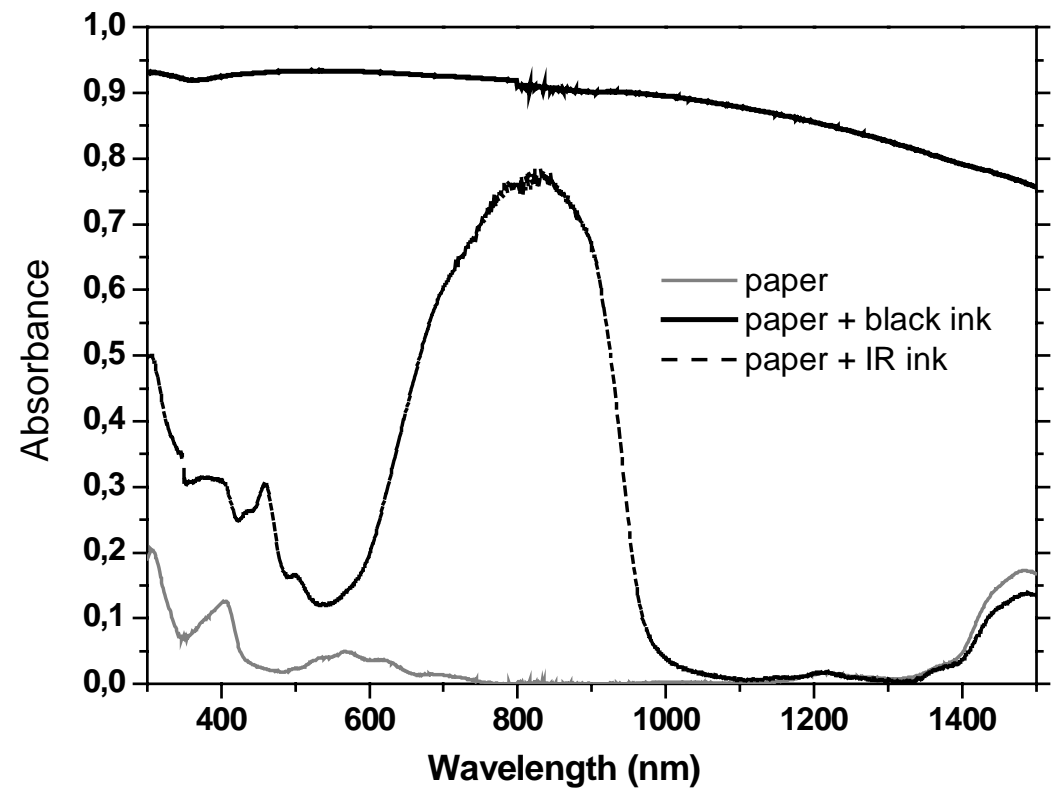

Figure 4 : Absorbency spectra of white paper and the same paper inked with black or infrared inks.

\section{RESULTS}

Fig. 5a shows the cut obtained with the laser on a paper inked with a black marker, at a laser speed of $1.2 \mathrm{~m} / \mathrm{min}$. It should be underlined that when the laser moved outside the black inked area, it even not left a mark on the paper. It proves the necessity of a suitably absorbing ink.

Experiments were also performed on paper inked using a desktop printer, either a laser printer or an inkjet printer. In contrast with inking made using a pen marker or our specially formulated ink, the ink of printers remains on the very surface of the paper, and does not penetrate within the paper. In all cases, it was stated that the laser ablation was limited to the very surface of the paper: only the superficial ink layer was removed. This observation is coherent with the use of laser in cleaning superficially stained paper $^{9}$ for art conservation, or for generating media with tactile characteristics through ink ablation ${ }^{10}$.

Figure 6 provides closer views of the laser cut on a paper inked using the black marker ink.

Further cutting experiments were also performed on paper marked using the IR absorbing invisible ink. It was found that slightly slower paper displacement speeds were required to obtain a complete cut. Fig. $7 \mathrm{a}$ gives a view of a complete cut obtained at $0.8 \mathrm{~W}$ laser power, and at $0.75 \mathrm{~m} / \mathrm{min}$. The marking IR absorbing ink is not visible. The cutting width is coherent with the spot diameter which is estimated about $30 \mu \mathrm{m}$.

For higher displacement speeds of the laser on the inked paper, it is observed that the cut is not performed all through the paper. A view of such incomplete cut is given on fig. $7 \mathrm{~b}$.

A complete investigation as a function of laser power and laser speed was performed on paper both inked with black marker ink and invisible ink. Results are displayed on figure 8. It is observed that a minimum power of $0.2 \mathrm{~W}$ is required to cut the inked paper. For significantly higher laser power, the speed at which complete cut of the paper occurs increases linearly with the available power. Black marker ink is obviously more efficient, since the ratio of the power by the threshold cutting speed is about $0.28 \mathrm{~J} / \mathrm{cm}$ fusing black ink, while it is of $0.5 \mathrm{~J} / \mathrm{cm}$ using IR absorbing invisible ink. This is attributed to incomplete laser absorption of paper inked with the invisible dye, and possibly to a degradation of the optical characteristics of the dye during the interaction process with the laser. 

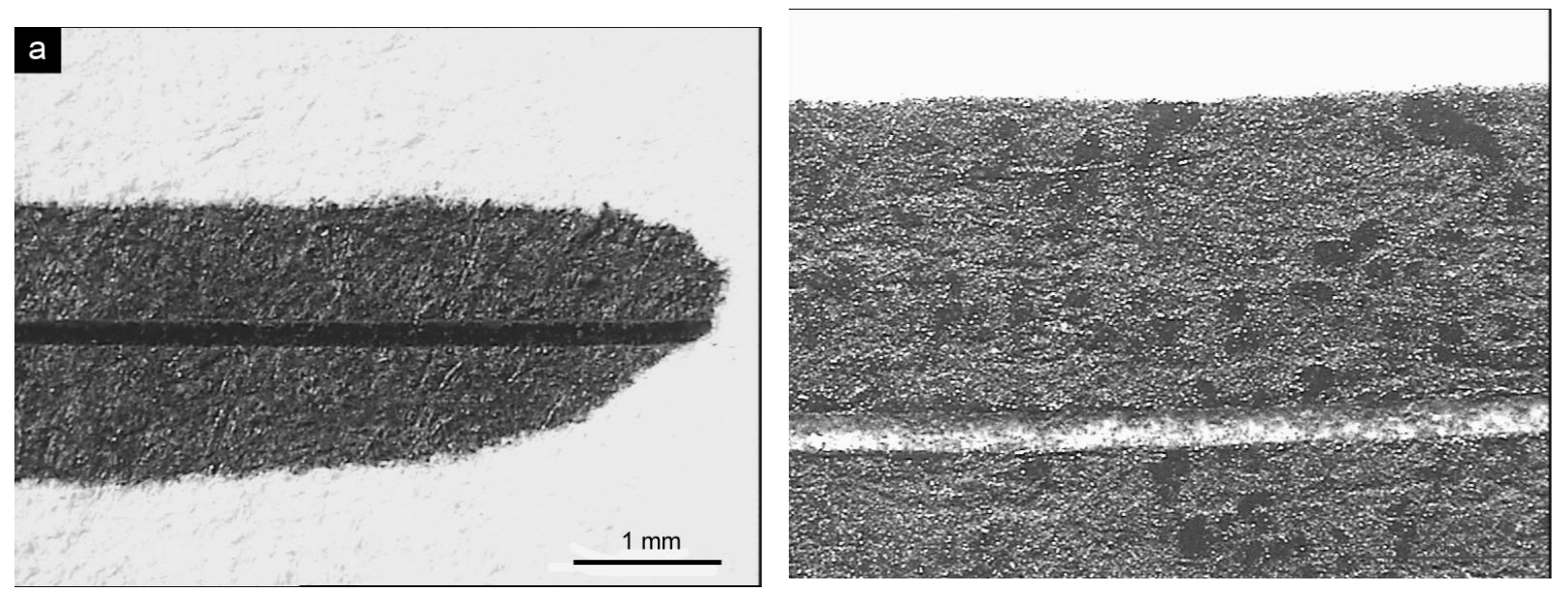

Figure 5 : laser processing of inked paper : a) complete cut of the paper obtained on a mark made using a black marker b) superficial ablation of the ink deposited using a laser printer
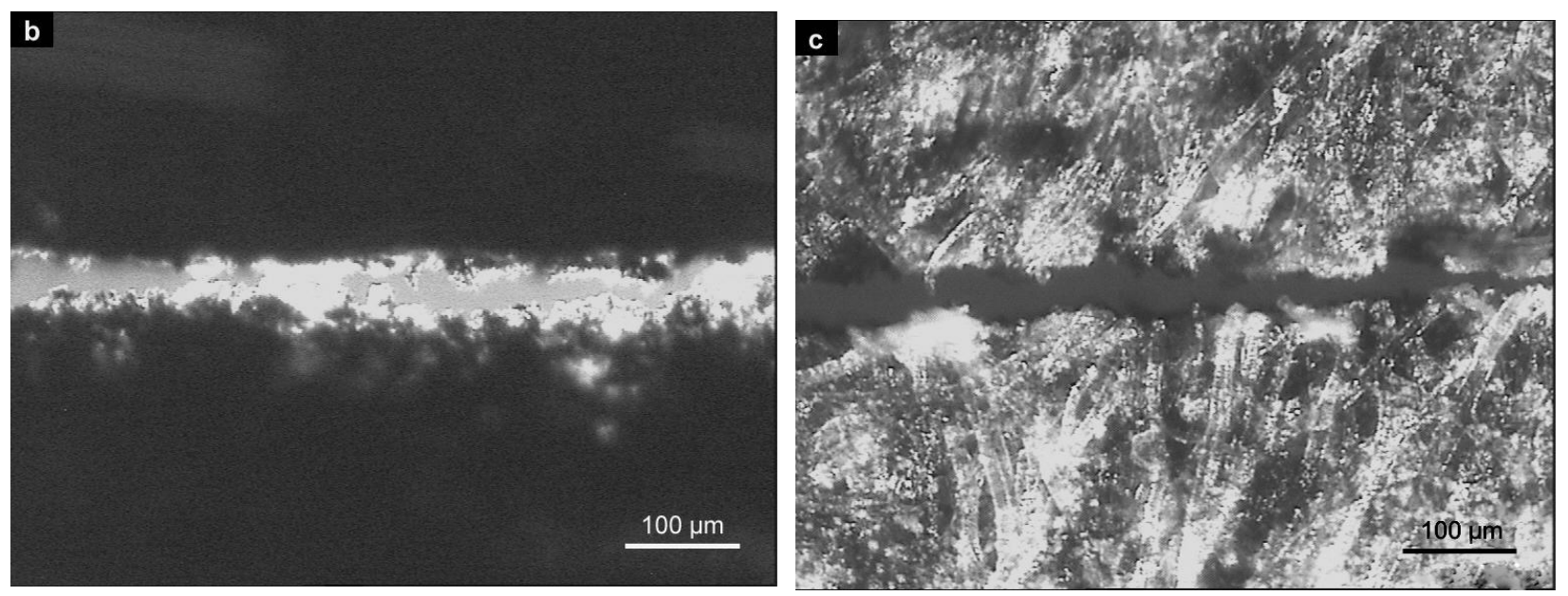

Figure 6 : laser cut of a paper inked using a black absorbing ink; b) inking and laser attack side; c) back side

The processing of inked paper at laser speeds higher than the threshold cutting speed is useful, since it can produce easily tearable lines, and easy folding lines. For speed over power ratio that are comprised between $100 \%$ and $120 \%$ of the threshold, the laser produces easy separation lines. It is easy to tear apart the two pieces of paper separated by such a line. The result is very tidy. For power over speed ratio comprised between $120 \%$ and $200 \%$ of the cutting threshold, easy folding lines are obtained. Laser processing proves to be a convenient way to score the paper, that can then be folded into three-dimensional objects. The folding lines are very tidy. 

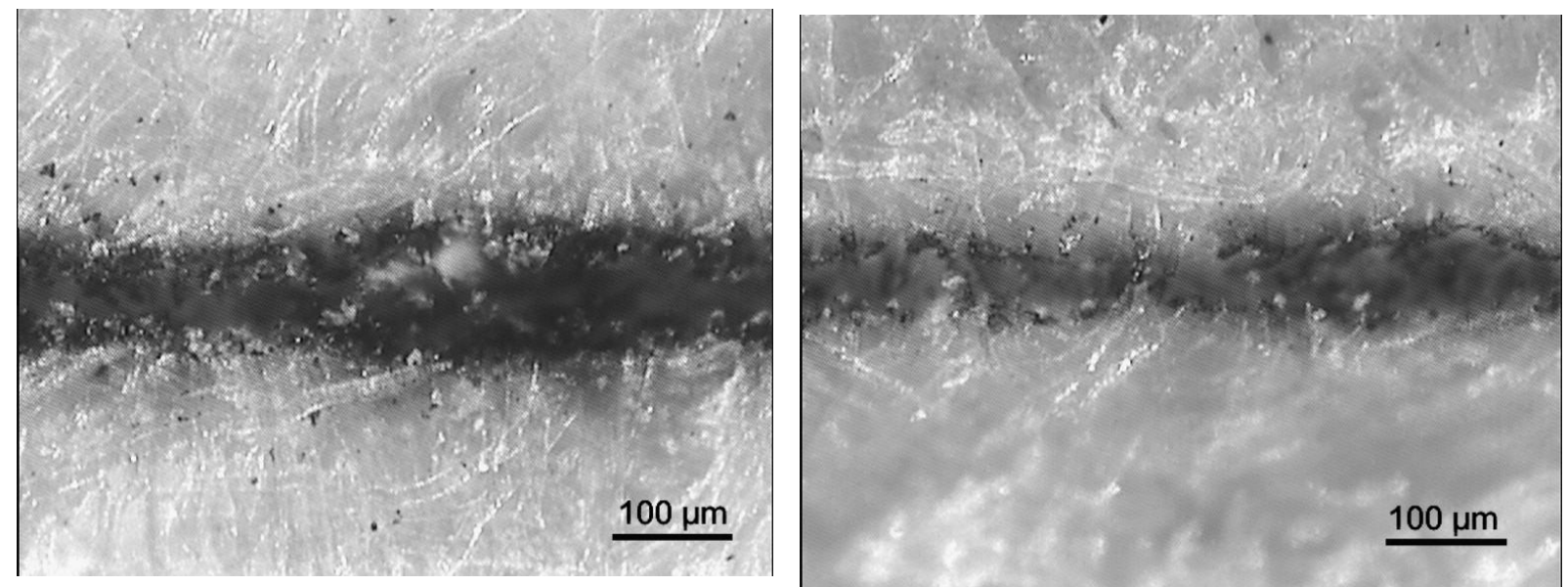

Figure 7: laser cut of paper inked using an invisible absorbing ink; left: complete cut obtained with a cutting speed of $0.75 \mathrm{~m} / \mathrm{min}$; right : incomplete cut obtained with a laser speed of $1.2 \mathrm{~m} / \mathrm{min}$.

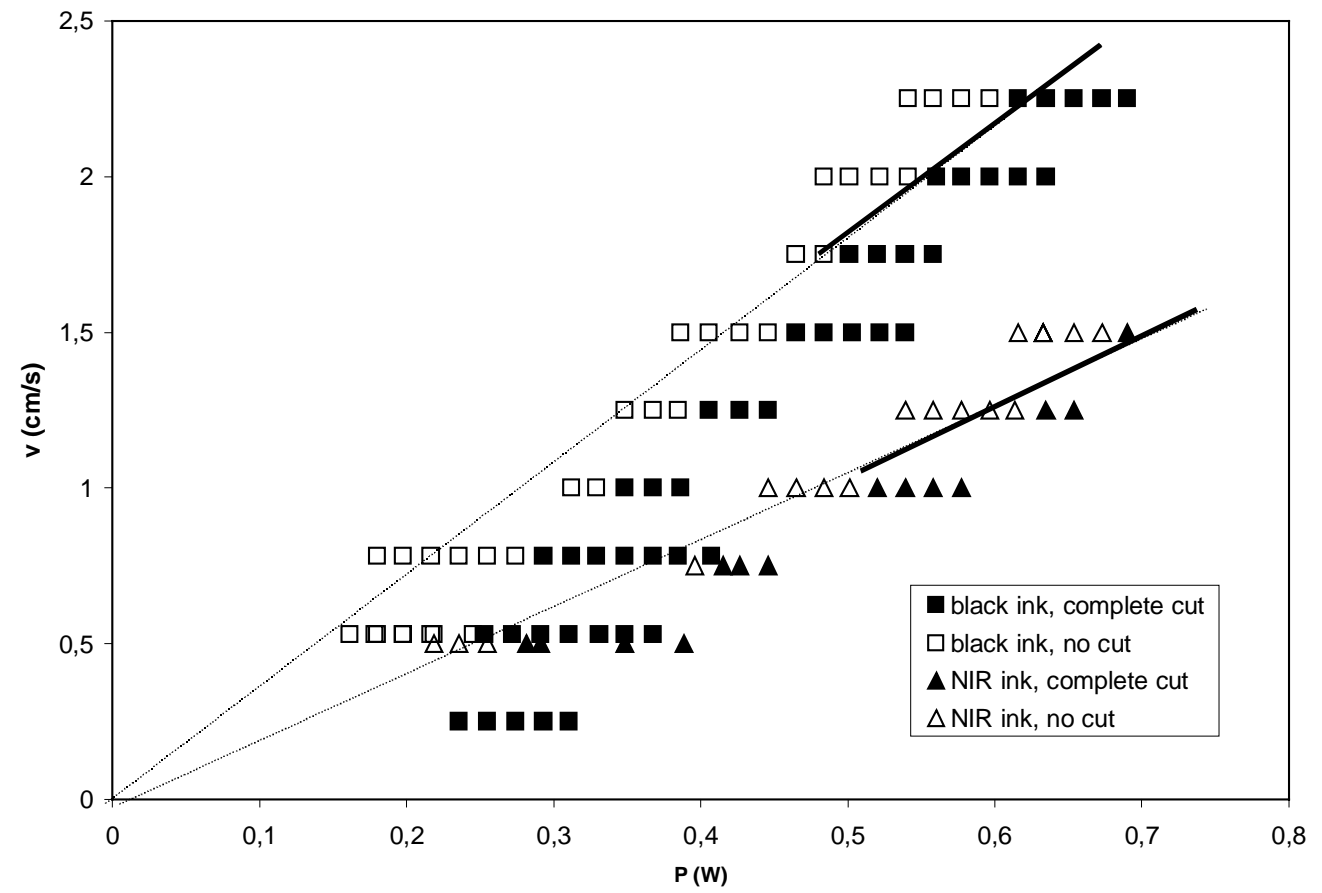

Figure 8 : cutting performance recorded at different laser powers and laser speeds, for black ink (squares) and "invisible ink" (triangles). Full marks correspond to complete cut, and hollow mark correspond to incomplete cut. The lines describe the asymptotic dependence of the maximum cutting speed with the laser power. 
The cutting of stronger paper, with surface weight up to 3 times that of conventional office paper, has also been achieved. It was found that for a given laser power, the cutting speed is nearly proportional to the inverse of the weight of the paper.

Experiments have also been conducted on photo paper. It has been found that the glossy surface to be printed is quite impermeable to the absorbing ink, which is detrimental to the quality of the cut. A solution was found by inking the paper on the back side with the invisible ink, and good quality results were then obtained.

The influence of the quality of the beam focusing has also been investigated. As expected, it is observed that the higher cutting speeds are obtained when best focus is obtained.

The influence of the thermal properties of the substrate supporting the paper has also been investigated. In particular, it has been shown that when the underlying support material has a low thermal conductivity, the combustion zone of the paper extends to a width significantly larger than the spot width, and a flame may be visible. The result is not tidy. A similar effect can be observed when the paper is not properly applied against its metallic support.

\section{DISCUSSION}

It is interesting to compare the lineic energy $\mathrm{E}_{\mathrm{l}}$ required to cut a unit of length in our experiments and in conventional $\mathrm{CO}_{2}$ system. Reference 1 gives indications on high power $\mathrm{CO}_{2}$ lasers used in the paper conversion industry. The cutting speed reported for a $250 \mathrm{~W}$ laser on $75 \mu \mathrm{m}$ thick paper corresponds to $\mathrm{E}_{\mathrm{l}}=0.9 \mathrm{~J} / \mathrm{cm}$ energy, that of a $70 \mathrm{~kW}$ laser is about $2.6 \mathrm{~J} / \mathrm{cm}$. In our experiments, we achieved lineic energies $\mathrm{E}_{\mathrm{l}}=0.5 \mathrm{~J} / \mathrm{cm}$ using our invisible ink, and as low as $\mathrm{E}_{\mathrm{l}}=0.28 \mathrm{~J} / \mathrm{cm}$ using black ink. This shows that though industrial $\mathrm{CO}_{2}$ paper cutting systems differ by several order of magnitudes from our system devised for desktop printing, lineic energies required for cutting are comparable. We achieve somewhat better efficiency in our system, possibly because of better focusing.

A very simple model can be proposed to account for $E_{l}$. The paper is supposed to degrade at a temperature $T_{d}$; the radial profile of the laser beam is assumed to be uniform over a disk of radius $\mathrm{R}$; the deposition of heat within the paper is supposed to be uniform over a thickness $\delta$ (related to the features of optical absorption of the paper at the laser wavelength); and heat transfer between the paper and the environment is neglected. Under these circumstances, an order of magnitude of the energy per unit length $\mathrm{E}_{1}$ can be expressed as :

$$
\mathrm{E}_{1}=\frac{\mathrm{P}}{\mathrm{V}}=\frac{\rho \pi \mathrm{R} \delta \mathrm{C}_{\mathrm{p}} \Delta \mathrm{T}_{\mathrm{d}}}{2}
$$

where $\rho$ and $C_{p}$ are the density and specific heat of paper, and $\Delta T_{d}=T_{d}-T_{a}$ is the temperature elevation from the ambient temperature $T_{a}$ to the degradation temperature $T_{d}$.

Applying formula (1) with the following numerical values : $\rho=800 \mathrm{~kg} / \mathrm{m}^{3}$ (corresponding to $80 \mathrm{~g} / \mathrm{m}^{2}$ paper grade), $\mathrm{R}=$ $30 \mu \mathrm{m}$ (value representative of our experiments), $\delta=$ paper sheet thickness $=100 \mu \mathrm{m}, \mathrm{C}_{\mathrm{p}}=1500 \mathrm{~J} / \mathrm{kg} / \mathrm{K}$ (measured by DSC) and $\Delta \mathrm{T}_{\mathrm{d}}=400 \mathrm{~K}$ (temperature elevation at which the paper turns into flame), one obtains for $\mathrm{E}_{1}$ the value of 0.02 $\mathrm{J} / \mathrm{cm}, i$. e. about one order of magnitude less than the $\mathrm{E}_{1}$ values observed experimentally. The simplistic model described above must therefore be improved in order to better account for the different physical phenomena that occur in the laser paper cutting experiments. In particular, one may suspect that the energy required to degrade the paper is significantly larger than the evaluation introduced in this model. In addition, thermal diffusion of the heat produced by the laser should not be neglected. Though the presence of the substrate with a high thermal conductivity may increase the lineic energy required to obtain a complete cut, our experiments proved that it is absolutely essential that the substrates acts as a heatsink in order to avoid uncontrolled combustion of the paper.

Though in our experiments the inking has been done with a fountain pain, the possibility of performing the inking using an inkjet printer is being demonstrated. Consideration on chemistry have been used to find proper solvent, in order to have a proper penetration of the ink in the paper, and a proper viscosity; results shall be reported elsewhere. Inkjet printers are now achieving much more challenging material deposition issues ${ }^{11}$.

Price quotations for $1 \mathrm{~W} \mathrm{cw}$ laser diodes are in the $30 \$$ to $40 \$$ for large quantities. Mass-produced focusing optics adapted to laser diodes have been developed for CD and DVD industry, and are expected to be cheap. As a consequence, the key components that should be added to inkjet printers to perform cutting and scoring operations are 
compatible with mass-market applications. The cutting speeds of $1.2 \mathrm{~m} / \mathrm{min}$ achieved for $1 \mathrm{~W}$ optical power and invisible ink is compatible with a few pages per minutes throughputs common to personal printers. The speed can be increased by a factor of 5 using commercially available $5 \mathrm{~W} \mathrm{cw}$ laser diodes. This gives opportunities for market segmentation, with higher throughput and more expensive products on the one hand, and cheaper and slower products on the other hand. The expected decrease of the price per Watt of optical power may further drive replacement market for years.

It should be mentioned that an already successful development of laser processing of material using an IR absorbing pigment transparent in the visible range has been reported. It consists in laser welding transparent polymer films using a NIR laser ${ }^{12,13}$.

\section{APPLICATIONS AND MARKETS}

\subsection{Existing markets addressed through pre-formatted supports}

The requirement for special format outputs in digital printing is presently addressed through a variety of special format media, or precut media. Special format photo-paper, CD labels, fancy Christmas greeting cards, are very commonly marketed media that address these needs. For business applications, a much larger variety of pre-cut media exist, from address labels to badge name cards, or from fancy stickers to thumbnail organizers ${ }^{14}$.

Many other needs for special format support are addressed through conventional printing companies, that generally use dye cutting to make special shapes.

The possibility of addressing the market of special format through a cutting and scoring ability in the printer is a very clear advantage, since it does not require to buy a special format media for each application, creation is easy, and format can be tailored to the precise needs of the user through proper software.
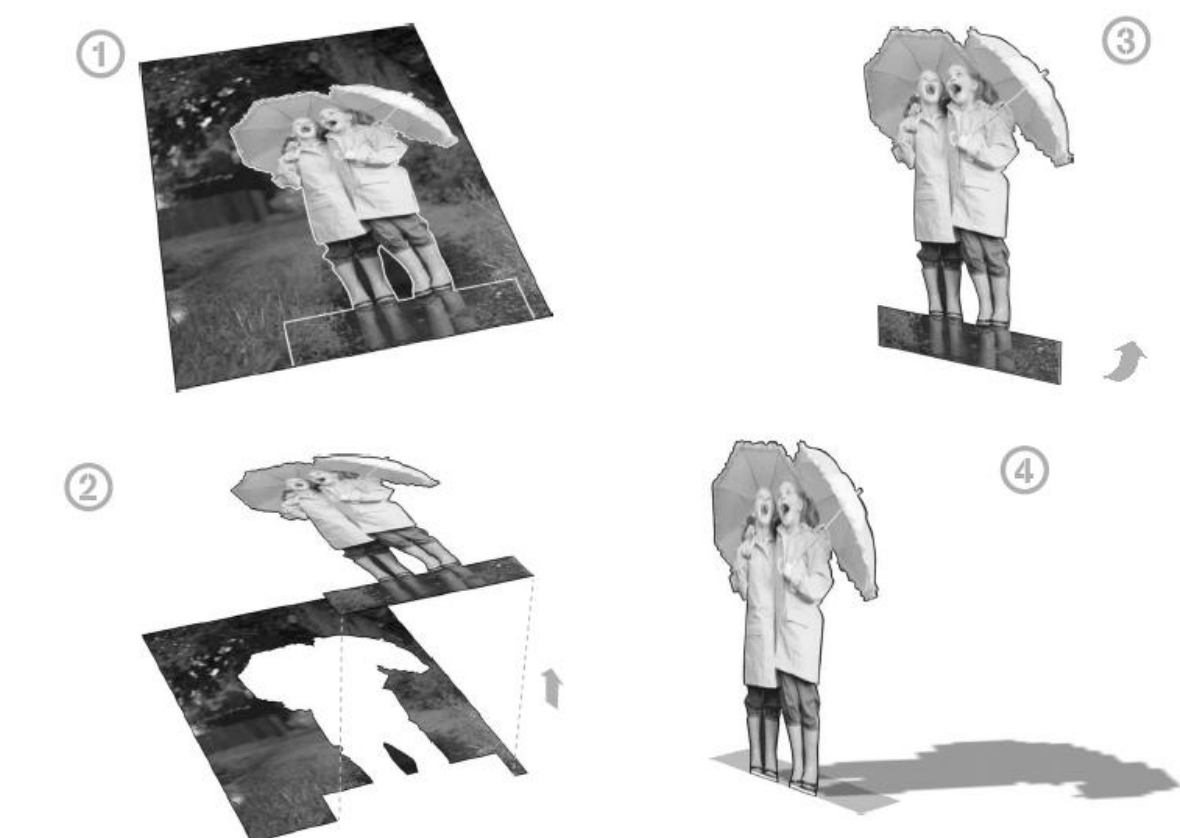

V2 Getting the photos out of the album

Figure 9: illustration of a possible use of paper cutting ability within a desktop printer, associated to Digital Imaging and Printing. 

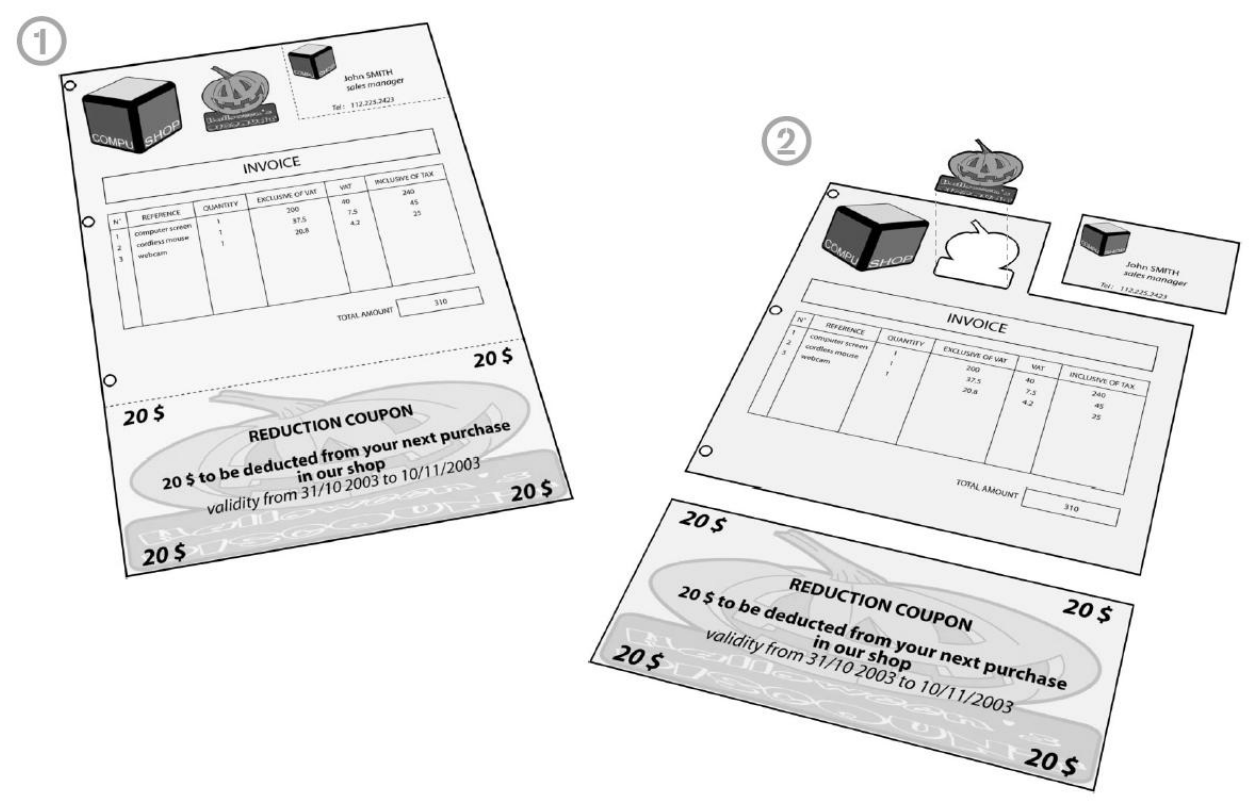

V2 More value into $\mathrm{A} 4$ pages by detaching slips

Figure 10: illustration of a possible use of paper cutting ability within a desktop printer, associated to office and small business applications.
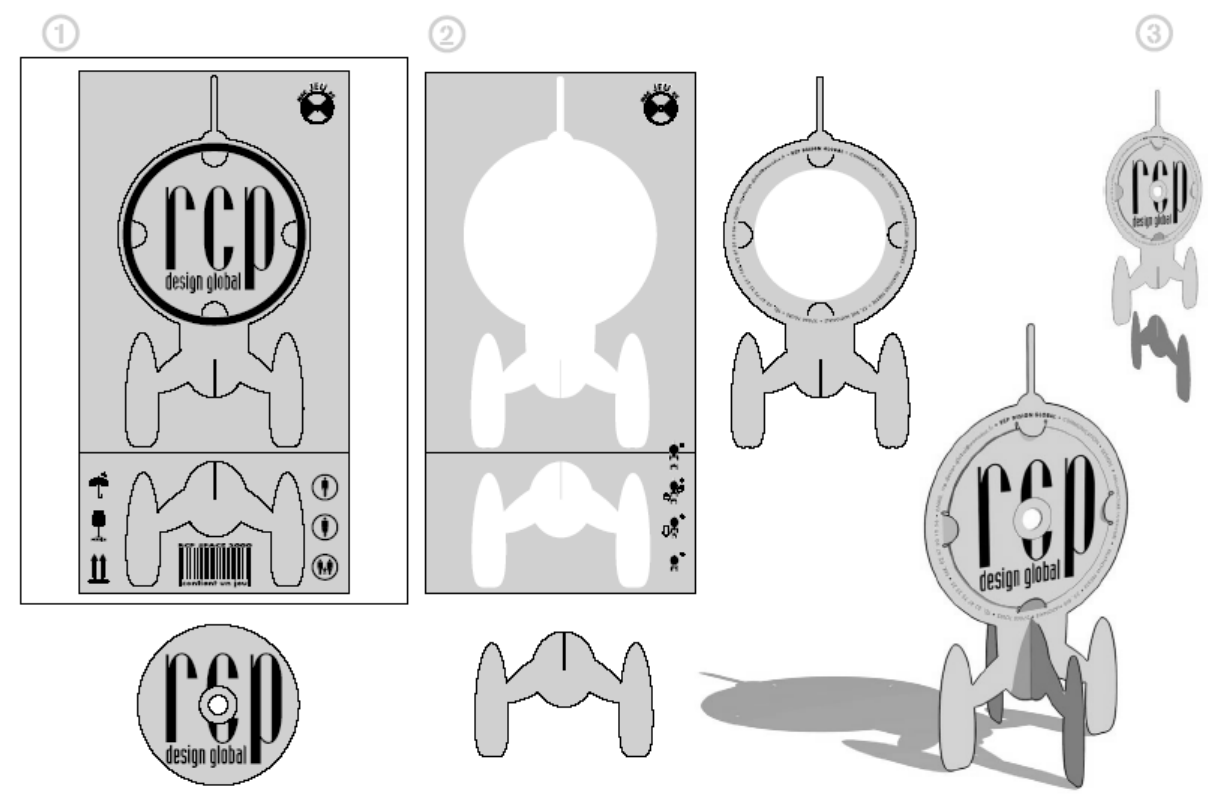

v2

Flat paper gets $3 \mathrm{D}$

Figure 11: illustration of a possible use of paper cutting ability within a desktop printer, associated professional graphics applications. 


\subsection{Print and Cut systems for the sign industry}

A straightforward process to cut thin sheet media is to use knives and blades. The sign industry has been using successfully mechanical cutting on so-called "cutting plotter" for years ${ }^{15}$. These systems require special vinyl media, and they are not intended to cut paper. They are not able to cut any shape, since the curvature radius of the cutting that this systems can performed is limited. Recently, print-heads have been added to some of these systems. These "Print and Cut" systems are well suited for the sign industry, but they are not adapted to office paper media.

\subsection{Perspectives for desktop cutting applications and markets}

Laser cutting of light material has been investigated as a possible first step toward desktop personal fabrication devices, in particular by the MIT MediaLab. In particular, "Desktop Fabrication" and "LaserLogo" from the Grassroots Invention Group, or "Personal fabrication" Special Interest Group ${ }^{16}$, report possible future uses of laser cutting of material. But it does not seem that printing and laser cutting of paper has been envisioned in these works.

The applications of this technique is not only in moving the value from special formats media to the desktop printing machine by addressing already existing applications. It clearly expands creation ability in the area of Digital Photography (see Fig. 9), office and small business organization (Fig. 10.), and graphics creation (Fig. 11). Of course, this makes sense only if software used for these applications assist the user in including cutting and scoring features. In turn, it opens significant opportunities for new softwares or updated version of existing softwares that would include this possibilities.

\section{CONCLUSION}

We have addressed the question whether laser processing of materials may have mass-market applications in the next years. For simple price reasons, we found this is possible in the near future only if such application requires single emitter laser diodes emitting in the NIR. Such lasers have been demonstrated with powers up to $11 \mathrm{~W}$, they are commercially available with powers up to $5 \mathrm{~W}$, and the present cost is less than $40 \$$ for $1 \mathrm{~W}$. These orders of magnitudes suggest that only thin materials can be processed, with a moderate speed. As a consequence, paper is a good material candidate for such mass market application. However, though laser cutting of paper is a well-proven industrial technique, laser diodes emitting in the NIR can not cut plain office paper because the optical properties of the paper are not suitable for that: white paper remains white, and therefore non absorbing, in the NIR. We have shown that using suitable inks that are absorbing at the wavelength of the laser, very tidy cut could be obtained, with cutting speeds ranging from $1.2 \mathrm{~m} / \mathrm{min}$ to $6 \mathrm{~m} / \mathrm{min}$ for powers ranging from 1 to $5 \mathrm{~W}$. These speeds seem compatible with desktop digital printing applications. In addition, the digital printing environment provides easily solutions to dispose properly the absorbing ink, and to computer-assist the whole creation and realization process.

While laser diodes have first reach mass market through storage applications (CD players), further extended trough digital printing and telecom applications (laser printers, fiber optics), high power laser diodes may reach mass market through a material processing application in close connection with digital printing. This innovation may be viewed as a first step into desktop laser-assisted personal fabrication devices.

\section{REFERENCES}

1. G. Chrissolouris, Laser Machining Theory and Practice (Springer Verlag, New York, 1991).

2. F. Bachmann, "Industrial applications of high power diode lasers in materials processing", Appl. Surf. Sci 208-209, 125-136 (2003).

3. A. Al-Muhanna, L.J. Mawst, D. Botez, D.Z. Garbuzov, R.U. Martinelli and J.C. Conolly, "High-power (>10 W) continuouswave operation from 100- $\mu$ m-aperture 0.97- $\mu$ m-emitting Al-free diode lasers", Appl. Phys. Lett. 73, 1182-1184 (1998).

4. A. J. Sellen and R. H. Harper, The myth of the paperless office (The MIT Press, Cambridge, 2002).

5. Lyra Research, www.lyra.com

6. $\quad$ www.verslaser.com

7. see www.cea-technologies.com/article/article.php?article $=379$

8. O. Acher, "Peripheral which can be used to print and cut sheets of paper using a low-power laser source", Patents WO2004069542; and also FR2850308

9. W. Kautek, S. Pentzien, P. Rudolph, J. Krüger and E. Konig, "Laser interaction with coated collagen and cellulose fibre composites: fundamentals of laser cleaning of ancient parchment manuscripts and paper", Appl. Surf. Sci. 127-129, 746-754 (1998). 
10. R. Stewart, L. Li and D. Thomas, “Multipass laser ablation of three coloured ink from a paper substrate”, J. Mater. Process. Technol. 114, 161-167 (2001).

11. H. Sirringhaus and T. Shimoda, "Inkjet printing of functional materials", MRS bulletin 28, 802-806 (2003).

12. see www.clearweld.com

13. L. P. Frieder and G. MacGrath, "Welding with lasers", Med. Device Technol. 13, 56 (2002).

14. see for example www.avery.com

15. see for example www.rolanddg.com; www.graphtecusa.com

16. see these projects at http://gig.media.mit.edu/projects.html 